\title{
Monoclonal antibodies to inner ear antigens: II Antigens expressed in sensory cell stereocilia
}

\author{
Martin Ptok *, Thankam S. Nair, Richard A. Altschuler, Jochen Schacht and Thomas E. Carey \\ Kresge Hearing Research Institute, The University of Michigan, Ann Arbor, Michigan, U.S.A.
}

(Received 15 January 1991; accepted 3 August 1991)

\begin{abstract}
To develop biological reagents for investigating structure-function relationships in the organ of Corti, wc have raised monoclonal antibodies, (MAb) to inner ear tissues. Our first series of antibodies prepared after intrasplenic immunization of mice with guinea pig tissues, identified antigens restricted to supporting cell structures, but no hair cell specific antibodies were developed [Zajic et al., Hear. Res. 52, 59-72, 1991]. In this report we describe the isolation, binding specificity and initial characterization of the stereocilia-binding monoclonal antibodies, KHRI-4, and KHRI-5. Mice were immunized with avian, amphibian and mammalian sensory hair cell-containing tissues and antibodies were screened for selective binding to cochlear extracts in ELISA. In the inner ear, KHRI-4 and KHRI-5 bind specifically to stereocilia in both avian and mammalian cochlear and vestibular tissue preparations using immunofluorescence and immunoperoxidase assays. In other tissues only certain cells of mesothelial origin, such as smooth muscle in gut and the arteriolar vasculature, were stained by KHRI-4 indicating that the antigenic structure defined by this antibody has limited distribution. KHRI-5 binding could be detected in other tissues only at high antibody concentrations suggesting that the gene product identified by this antibody is also weakly expressed in other cell lineages. Western blot analysis showed that KHRI-4 and -5 detect different protein complexes. KHRI-4 identifies an antigenic structure common to gut, cochlea, vestibular tissue and cultured fibroblasts consisting of a $\sim 195$ and a $230 \mathrm{kDa}$ heterodimer designated p195/230. KHRI-5 binds to a prominent $\sim 200-210$ $\mathrm{kDa}$ band in Western blots of cochlear tissues, gut and fibroblasts. In immunoprecipitation experiments, KHRI-5 precipitated three proteins of $M_{\mathrm{r}} \sim 200-210,230$ and $260 \mathrm{kDa}$ indicating that the $\sim 200.210 \mathrm{kDa}$ protein carrying the epitope for this antibody is a member of a heterotrimer complex. Our results show that these protein complexes are structural components of stereocilia and that the same proteins are arrayed in conjunction with the actin stress fibers of cultured mesothelial cells. Thus, they are likely to be important for maintaining the actin structure of stereocilia essential to transduction in sensory hair cells.
\end{abstract}

Cochlea; Monoclonal antibodies; Hair cells; Stereocilia

\section{Introduction}

It has been our goal to develop monoclonal antibodies to cochlear tissues that might serve as probes of cochlear structure and function. In our previous study, immunization of mice with isolated guinea pig outer hair cells (including attached supporting cells) resulted in hybridomas that produced monoclonal antibodies to antigens on supporting cells in the organ of Corti (Zajic et al., 1991). Subsequently, we found that guinea pigs immunized with chick inner ear homogenates developed serum antibodies that bound to hair cell stereocilia in both chick and guinea pig inner ears in immunocytochemical assays (Orozco et al., 1990). There was also a transient hearing loss in the immunized animals suggesting that the immune response to inner

\footnotetext{
* Present address: University HNO Klinik, Silcherstrasse 5, W-7400 Tübingen, F.R.G.

Correspondence to: Thomas E. Carey, Kresge Hearing Research Institute, The University of Michigan, 1301 East Ann Street Ann Arbor, MI 48109-0506, U.S.A. Fax: 313-764-0014.
}

ear antigens might disturb inner ear function possibly through antibody binding to hair cell stereocilia.

In the present study we investigated whether such a cross species immunization would provide a sufficient challenge to the immune system to generate monoclonal antibodies to hair cell structures. Monoclonal antibodies were developed that had immunoreactivity similar to the antibodies that we had previously observed in the sera of animals that dcvcloped a hearing threshold shift after immunization with inner ear antigens. These new monoclonal antibody reagents should make it possible to characterize the nature of the immunogenic molecule(s) on stereocilia and should help us to deduce their function in the hearing transduction process.

\section{Materials and Methods}

\section{Animals}

Pathogen-free BALB/c mice (Charles River Lab, Wilmington, MA) and pigmented guinea pigs (Murphy's 
Breeding Lab, Plainfield, IN) were housed under the surveillance of the Unit for Laboratory Animal Medicine, University of Michigan, MI. Chicks were obtained 5-7 days after hatching from Kingswheel Farm, Mount Vernon, OII and used on the day of delivery. Frogs were obtained from NASCO, Fort Atkinson, WI. and were maintained in freshly prepared artificial pond water at ambient temperature (21$\left.22^{\circ} \mathrm{C}\right)$

\section{Immunization and fusion}

Mice were sequentially immunized with hair cell containing tissues from three different species: from frogs (Xenopus laevis), lateral line 'stitches'; from guinea pigs, organ of Corti; and from chicks, basilar papillae. For each immunization, the tissues were prepared immediately after euthanasia of the donor animals. The frog lateral line skin was excised and the stitches were dissected; the guinea pig organ of Corti was stripped from the basilar membrane and the spiral limbus; isolated hair cells were dissected as described previously (Zajic and Schacht, 1987); chick basilar papillae were dissected from the cartilage, the tegmentum vasculosum and the eighth cranial nerve were removed, and the tissues were homogenized with a glass tissue grinder in phosphate buffered saline (PBS).

The monoclonal antibodies (mAbs) described in this report were obtained from a fusion using the spleen of a female $\mathrm{BALB} / \mathrm{c}$ mouse that was immunized 6 times in two week intervals as follows: The first immunization consisted of intraperitoneal (i.p.) injection of tissues containing approximately 1000 frog neuromasts (60) 'stitches' $\sim 200 \mu \mathrm{g}$ protein). The second immunization contained approximately $150 \mu \mathrm{g}$ protein from 6 guinea pig cochleae; the third contained $1.5 \mathrm{mg}$ prorein from 10 chick basilar papillac; the fourth immunization contained a mixture of 500 frog neuromasts (approximately $100 \mu \mathrm{g}), 150 \mu \mathrm{g}$ protein from 6 guinea pig cochleae and $1.5 \mathrm{mg}$ protein from 10 chick basilar papillae; the fifth contained approximately $5 \mu \mathrm{g}$ protein from 6 guinea pig cochleae and the sixth contained approximately 1000 isolated hair cells (Schacht and Zenner, 1987; Zajic and Schacht, 1987) from 6 guinea pig cochleae. This final immunization was injected directly into the spleen (Spitz et al., 1984; Spitz, 1986). Three days after the last injection, the mouse was killed and the spleen was removed for preparation of hybridomas.

The spleen cells were fused with $\mathrm{SP} 2 / 0$, a nonsecreting murine myeloma line, using $33 \%$ polyethylene glycol 1000 (Koch-Light Laboratories, Berks, U.K.) following the protocol of Köhler and Milstein (1975) as described previously by Kimmel and Carey (1986). Fused cells were cultured in 96-well plates $\left(10^{5}\right.$ cells per well) in Iscove's modified Dulbecco's medium
(IMDM; Gibco) containing $20 \%$ fetal bovine serum, 2 $\mathrm{mM}$ L-glutamine, $100 \mathrm{IU} / \mathrm{ml}$ penicillin, $100 \mu \mathrm{g} / \mathrm{ml}$ streptomycin, $10^{-4} \mathrm{M}$ hypoxanthine, $1.6 \times 10^{5} \mathrm{M}$ thymidine and $4 \times 10^{-7} \mathrm{M}$ aminopterin. After 10 days, hybridoma supernatants were tested for antibody production by enzyme-linked immunosorbent assay (double-antibody sandwich ELIS $\Lambda$ ) and antibody secreting cells were subcloned by limiting dilution. The screening was repeated and selected clones were subcloned again.

\section{Screening methods and antibody subtype classification}

To test for initial antibody specificity, enzyme linked immunosorbent assays (ELISA) were performed in microtiter plates coated with tissue homogenates as described previously (Zajic et al., 1991). Guinea pig cochlea (frecze-thawed organ of Corti strips, ultrasonicated for $3 \mathrm{~min}$ ), or brain, lung, spleen, liver, kidney, or skeletal muscle homogenized (Polytron, Brinkman Instruments, Lucerne, Switzerland) to a tissue concentration of $1 \mathrm{~g} / 10 \mathrm{ml}$ of buffer, (0.01 M HEPES, pI 7.4 , containing $0.25 \mathrm{M}$ sucrose and the protease inhibitors phenyl methyl sulfonyl fluoride (PMSF)( $1 \mathrm{nM}$ ), leupeptin $1 \mu \mathrm{g} / \mathrm{ml}$, antipain $2 \mu \mathrm{g} / \mathrm{ml}$, benzamidine 10 $\mu \mathrm{g} / \mathrm{ml}$, aprotinin $10 \mathrm{KIU} / \mathrm{ml}$, chymostatin $1 \mu \mathrm{g} / \mathrm{ml}$, pepstatin $1 \mu \mathrm{g} / \mathrm{ml}$ ) were used. Screening assays were also performed using plates coated with similarly prepared tissues from chicks and frogs.

Plates were coated by incubation with $10 \mu \mathrm{g} / \mathrm{ml}$ of protein overnight at $4^{\circ} \mathrm{C}$. Coated ELISA plates were stored at $-20^{\circ} \mathrm{C}$ if not used immediately. Prior to use the wells were washed three times and then blocked with $5 \%$ non-fat dry milk, dissolved in PBS ( $\mathrm{pH} 7.5$ ), containing $0.01 \%$ Tween 20 . The wells were incubated for $1 \mathrm{~h}$ at room temperature with $100 \mu \mathrm{l}$ of hybridoma supernatant and then washed three times with PBS. The specifically bound mouse mAbs were detected by incubation for $30 \mathrm{~min}$ with biotinylated, affinity purified, horse antibody to mouse $\operatorname{IgG}(40 \%$ cross reactive with mouse IgM) (Vector Labs, Burlingame, CA) diluted 1:1000 in PBS containing 1\% horse serum. After three washes with PBS, $50 \mu 1$ of avidin-biotin-complex (ABC) conjugated to alkaline phosphatase (Vector Labs, Burlingame, CA) were added to each well and incubated for $30 \mathrm{~min}$ at room temperature. After five washes with PBS, $100 \mu l$ of $p$-nitrophenylphosphate (PNPP, $2 \mathrm{mg} / \mathrm{ml}$ ) in $100 \mathrm{mM} \mathrm{NaHCO}$ and $10 \mathrm{mM}$ $\mathrm{MgCl}_{2}, \mathrm{pH} 9.5$, were added and incubated for $15 \mathrm{~min}$. The reaction was stopped by addition of $50 \mu \mathrm{l}$ of $5 \mathrm{~N}$ $\mathrm{NaOH}$ and the absorbance of each sample was measured with an ELISA plate reader at $415 \mathrm{~nm}$ (Microplate Autoreader, Bio-tek Instruments, Vinooski, VT). Controls included wells that contained PBS or non secretor supernatant instead of the first antibody and other wells contained PBS instead of second antibody. 
The immunoglobulin subclass was determined using a sub-isotyping kit (Hyclone, Logan, UT). Microtiter plates were coated with goat anti mouse immunoglobulin. After application of the hybridoma supernatants (60 min) and washing, the isotyping antisera (rabbit anti mouse $\operatorname{IgM}, \operatorname{IgG} 1, \operatorname{IgG} 2 \mathrm{a}, \operatorname{IgG} 2 \mathrm{~b}, \operatorname{IgG} 3$ and $\operatorname{IgA}$ ) were added to different wells $(60 \mathrm{~min})$. This was followed by the addition of peroxidase-conjugated goat anti rabbit $\mathrm{IgG}$ for $60 \mathrm{~min}$, washing, incubation with the substrate $O$-phenylene diamine for $15 \mathrm{~min}$, and the absorbance was measured immediately at $490 \mathrm{~nm}$. All incubations were performed at room temperature.

\section{Cultured fibroblasts}

Fibroblasts were cultured from normal guinea pig skin in minimal essential medium containing $10 \%$ fetal bovine serum. Confluent cultures were harvested with $0.1 \%$ trypsin $/ 0.2 \mathrm{M}$ EDTA and transferred to sterile coverslips or $35 \mathrm{~mm}$ Petri dishes for subsequent study. For immunostaining experiments, fibroblast monolayers on coverslips at 70-80\% confluency were washed in PBS and used without fixation or were fixed and permeabilized in acetone

\section{Immunocytochemistry}

\section{Preparation of hair cell containing tissues}

Tricolored guinea pigs were deeply anesthetized with Urethane $^{\circledR}$ and perfused through the heart with PBS followed by $2 \%$ paraformaldehyde in PBS at $4{ }^{\circ} \mathrm{C}$. Temporal bones including cochleae were removed and fixed locally with the same fixative through the round window. For immunoperoxidase and immunofluorescence procedures, bony shell, vascular stria, tectorial membranes and Reissner's membranes were removed leaving spirals with the organ of Corti exposed which were rinsed in PBS at least 1 hour, as described in detail previously (Fex and Altschuler, 1981, 1986; Altschuler et al., 1985a, 1985b; Fex et al., 1985;). From the remaining temporal bone the ampules, saccule and utricle were dissected. The saccular membrane, and the roofs of the ampules and the utricle were opened. With a capsule knife the otoconia, gelatin layer, and subcupular meshwork and cupula were removed to allow antibody access to the epithelial surfaces. Chicks were euthanized with $\mathrm{CO}_{2}$ inhalation, temporal bones removed and the basilar papilla was exposed by quickly opening the middle ear and removing the stapes. These specimens were fixed with $2 \%$ paraformaldehyde for 1 hour and then washed in PBS for 1 hour. Triton X-100 $(0.01 \%)$ was added to the fixative to insure permeabilization. Basilar papillae were dissected approaching from medial. The tegmentum vasculosum was cut away and the tectorial membrane was removed with a fine forceps. Chick vestibular tissue was obtained using methods similar to those described above. Frogs were cooled on ice for $1 \mathrm{~h}$ and killed by decapitation. The skin was removed and the lateral linc organs cut out under a dissecting microscope. The skin strips containing neuromasts were fixed with $2 \%$ paraformaldehyde for $1 \mathrm{~h}$.

\section{Frozen sections of control tissues}

Fixed and fresh tissues (brain, tongue, heart muscle, skeletal muscle, lung, kidney, liver, spleen, skin) were also dissected from guinea pigs and chicks and prepared for frozen sections. 'l'issues were placed in O.C.T. Tissue-Tek embedding medium (Miles Scientific, Naperville, IL) and rapidly frozen in polypenthane prechilled in liquid nitrogen. Blocks were stored no longer than two weeks at $-80^{\circ} \mathrm{C}$. The blocks were sectioned on a Hacker-Bright cryotome. Frozen sections were transferred to gelatin subbed slides and dipped in cold acetone $\left(-20^{\circ} \mathrm{C}\right)$. These tissue sections were stored no longer than one week prior to processing. Before immunostaining the sections were air-dried for $30 \mathrm{~min}$ and fixed with $2 \%$ paraformaldehyde (5 $\mathrm{min})$ or were dipped into acetone $(10 \mathrm{~min})$ to insure that the tissues were thoroughly fixed and attached to the slide. Triton X-100 $(0.01 \%)$ was used to permeabilize paraformaldehyde fixed tissues.

\section{Immunoperoxidase procedures}

Prior to each incubation the specimens were washed three times for $3 \mathrm{~min}$ in PBS. In assays using chick basilar papillae an avidin-biotin blocking reagent (Vector Labs, Burlingame, CA) was employed to block non-specific binding of biotin to endogenous avidin. This blocking step was not necessary with the other species we tested. Blocking of non-specific second antibody binding was achieved by incubation with $3 \%$ horse serum for 10-30 min. Excess horse serum was removed from free floating whole mount preparations or blotted from slides and then incubated for $30 \mathrm{~min}$ with primary antibody (diluted either $1: 1,1: 5,1: 10$, $1: 20,1: 50,1: 100,1: 200)$. The slides were washed, and incubated in biotinylated anti mouse IgG or IgM diluted 1:200 for $30 \mathrm{~min}$. After washing, the specimens were incubated with the Vectastain horseradish peroxidase ABC reagent (Hsu et al., 1981) for $45 \mathrm{~min}$, washed and developed for $5 \mathrm{~min}$ with the peroxidase substrate solution (diaminobenzidine $0.5 \mathrm{mg} / \mathrm{ml}$ in PBS containing $0.01 \% \quad \mathrm{H}_{2} \mathrm{O}_{2}$ ). Slides were counterstained with Hematoxylin (Sigma, St. Louis, MO, USA) dehydrated in ethanol $(70 \%$ for $5 \mathrm{~min}, 100 \%$ twice for $5 \mathrm{~min}$, dipped in xylenc) and mounted wet in Krystalon (EM Diagnostic Systems, Gibbstown, NJ).

\section{Immunofluorescence}

Immunofluorescence staining was performed as described for immunoperoxidase staining except that in- 
cubation with avidin conjugated rhodamine (Vector Laboratories, Burlingame, CA) was substituted for the ABC complex. Slides were examined using a Leitz Orthoplan fluorescence microscope and photographed with a Kodak T-max 400 film.

\section{Immunoblotting}

Tissues were solubilized in lysis buffer ( $1 \% \mathrm{NP}-40$ in PBS containing protease inhibitors including $1 \mathrm{mM}$ PMSF, leupeptin $1 \mu \mathrm{g} / \mathrm{ml}$, antipain $2 \mu \mathrm{g} / \mathrm{ml}$, benzamidine $10 \mu \mathrm{g} / \mathrm{ml}$, aprotinin $10 \mathrm{ku} / \mathrm{ml}$, chymostatin 1 $\mu \mathrm{g} / \mathrm{ml}$, pepstatin $1 \mu \mathrm{g} / \mathrm{ml}$ ) on ice for $30 \mathrm{~min}$ and clarified by centrifugation $(11,000 \times \mathrm{g})$ in a microcentrifuge for $5 \mathrm{~min}$ at $4{ }^{\circ} \mathrm{C}$. Polyacrylamide gel electrophoresis in sodium dodecyl sulfate (SDS-PAGE) was performed according to the method of Laemmli (1970). For gels run under reducing conditions, tissue homogenates were boiled for $5 \mathrm{~min}$ in sample buffer containing $5 \% \mathrm{v} / \mathrm{v}$ 2-mercaptoethanol. Tissues homogenates prepared as described above and a prestained molecular weight standard (Amersham, Arlington Heights, IL, USA) were mixed with loading buffer (Tris-HCI, pH 6.8, 2\% SDS, $10 \%$ glycerol, $0.005 \%$ bromphenol blue) to a final concentration of 100-150 $\mu \mathrm{g}$ protein/sample/lane and loaded onto a $3 \%$ stacking and $7 \%$ separating SDS gel. The electrophoretically separated proteins were immunoblotted from the gel onto nitrocellulose paper (Millipore Corporation, Bedford, MA, USA) by the electrophoretic transfer method (Towbin et al., 1979). The paper was cut into strips and incubated overnight in blocking solution $(50 \mathrm{mM}$ Tris- $\mathrm{HCl}, \mathrm{pH} 8.0$, containing $5 \%$ nonfat dry milk, $2 \mathrm{mM} \mathrm{CaCl}_{2}$, and $5 \%$ Tween 20) (Johnson et al., 1983). These strips were incubated with supernatants from antibody producing clones (KHRI-4 and KHRI-5 each diluted 1:10 in blocking solution), with previously characterized antibodies (KHRI-3), with control IgM antbodies (UM-E7 and UM-1H12) to irrelevant antigens, with a commercially available antibody (Antikeratin 8.13 from Sigma, St. Louis, MO, USA) and supernatant from the myeloma line SP2 $/ 0$ for $30 \mathrm{~min}$. After washes in blocking solution the strips were incubated for $2 \mathrm{~h}$ in a 1:500 dilution of rabbit anti mouse IgM or rat anti mouse IgG (heavy and light chain specific) conjugated to horseradish peroxidase (Accurate Chemical and Scientific Corp., Westbury, NY), washed, and developed with 4-chloro-1-naphtol $(0.5 \mathrm{mg} / \mathrm{ml})$ in methanol-PBS pH $7.5(1: 5)$ containing $0.05 \% \mathrm{H}_{2} \mathrm{O}_{2}$. Color development was stopped by washing strips in water.

\section{Immunoprecipitation}

Fibroblasts grown in $35 \mathrm{~mm}$ Petri dishes were metabolically labelled with $\left[{ }^{35} \mathrm{~S}\right]$-methionine for $4 \mathrm{~h}$ in methionine-free medium. The plates were washed and the cells solubilized in lysis buffer (Dulbecco's PBS containing $1 \% \mathrm{NP}-40,1 \mathrm{mM}$ L-methionine, $1 \mathrm{mM}$ PMSF plus the cocktail of protease inhibitors described above). One hundred microliters of each lysate corresponding to one half of a $35 \mathrm{~mm}$ dish was mixed with $50 \mu \mathrm{l}$ of $1 \%$ bovine serum albumin $(10 \mathrm{mg} / \mathrm{ml}$ in sterile water) and $150 \mu \mathrm{l}$ of RIPA buffer $(50 \mathrm{mM}$ Tris, $\mathrm{pH} 8.0,150 \mathrm{mM} \mathrm{NaCl}, 0.1 \%$ SDS, $1 \%$ NP-40, $0.1 \%$ deoxycholate and $1 \mathrm{mM}$ PMSF) and precleared with 5 $\mu l$ second antibody (rabbit anti mouse IgG and IgM specific, Accurate Chemical, Old Westbury, NY) and $30 \mu \mathrm{l}$ protein A agarose (Sigma, St Louis, MO) for 30 min at $4^{\circ} \mathrm{C}$. After centrifugation at $1000 \times \mathrm{g}$, the supernatant was precleared a second time and incubated with $150 \mu \mathrm{l}$ of KHRI-4 or -5 or control (irrelevant antibody) hybridoma supernatant overnight at $4{ }^{\circ} \mathrm{C}$. Antigen-antibody complexes were precipitated with 10 $\mu \mathrm{l}$ of second antibody and $30 \mu \mathrm{l}$ of protein A agarose by incubation for $2 \mathrm{~h}$ at $4{ }^{\circ} \mathrm{C}$. After centrifugation at $11,000 \mathrm{rpm}$ for $2 \mathrm{~min}$ the superantant was removed and the pellet was washed 3 times in RIPA buffer, resupended in $50 \mu \mathrm{I}$ of reducing buffer (2-mercaptoethanol $5 \%(\mathrm{w} / \mathrm{v}), 0.0625 \mathrm{M}$ Tris-Cl $\mathrm{pH} 6.8,10 \%$ glycerol, $2 \%$ SDS, $0.005 \%$ bromphenol blue) boiled for $3 \mathrm{~min}$, loaded on a $3 \%$ stacking and $7 \%$ separating gel and electrophoresed (Laemmli 1970). The gels were stained, dried and autoradiographed.

\section{Results}

\section{ELISA-screening and subclass-typing}

From the original ten plates prepared from this fusion three hybridomas (KHRI-4, KHRI-5, KHRI-6) were identified based on strong and selective binding to extracts of guinea pig cochlea and chick basillar papilla in ELISA assays. These hybridomas were subcloned and pooled supernatants were prepared for complete analysis. All three antibodies were of the IgM class. After several months the hybridoma producing the KHRI-6 antibody stopped secreting. Since we were unable to recover a secreting population from this hybridoma, we discontinued the characterization of KHRI-6.

Immunocytochemical localization of antigen expression in tissues

Within the inner ear, monoclonal antibodies KHRI-4 and -5 showed highly restricted binding to stereocilia. Immunolabeling of both guinea pig and chick hair cell stereocilia by KHRI-4 and -5 are illustrated in Fig. 1 . Similar results were obtained with these antibodies by both immunofluorescence and immunoperoxidase 
methods (Fig. 1a-1g). There were no striking differences in staining between basal and apical turns, different rows of hair cells or cochleae from young (180-200 g) or older ( $350 \mathrm{~g}$ and more) guinea pigs. In the vestibular system both antibodies produced a filamentous labeling on the surface of the hair cells of utricle, saccule and all three ampules (Fig. 1e, 1g). In the basillar papilla no differences in immunolabeling were detected in the hair cell area near the superior or inferior, or the proximal or distal hair cell region (terminology according to Takasaka and Smith, 1971, 1978). Although both avian and mammalian inner ear tissues showed strong stereocilia staining, we were unable to demonstrate binding of the antibodies to stereocilia of the frog lateral line or any other structures in the frog skin.

Outside of the inner ear, labeling of smooth muscle cells in arterioles, gut, and bronchi was detected with KHRI-4. Fig. 2 shows an example of staining by KHRI-4 in a small arteriole. This type of focal staining was not observed with KHRI-5; instead, at high antibody concentrations, diffuse staining was observed in multiple cell types suggesting that low level expression of this antigen occurs in multiple tissue types. In both cases,
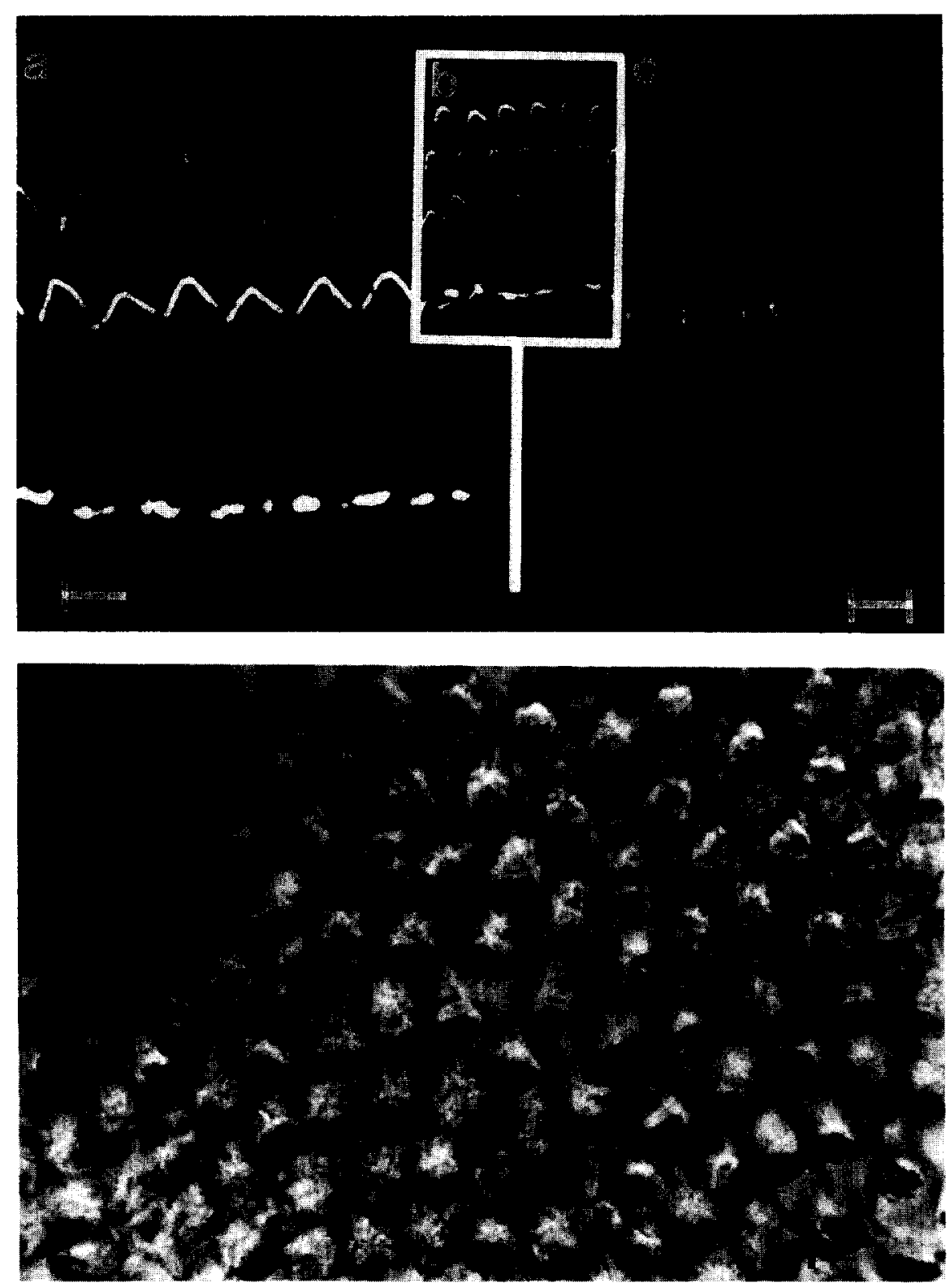

Fig. 1 (a-d). Photomicrographs showing immunofluorescent and immunoperoxidase staining of stereocilia in the organ of Corti and chick basilar papilla. (a) Focal plane showing predominantly the stereocilia of the first row of outer hair cells and those of the inner hair cells (scale bar $=10$ $\mu \mathrm{m}$ ). (b) (Inset) The same preparation photographed in a different focal plane to show that all stereocilia are similarly stained. (c) Control surface preparation incubated with supernatant from the SP2 $/ 0$ myeloma and second antibody (scale bar $=10 \mu \mathrm{m}$ ). (d) Immunoperoxidase staining of chick basilar papilla with KHRI-4 (scale bar $=5 \mu \mathrm{m})$. Fig. $1(\mathrm{e}-\mathrm{g})$ on next page. 


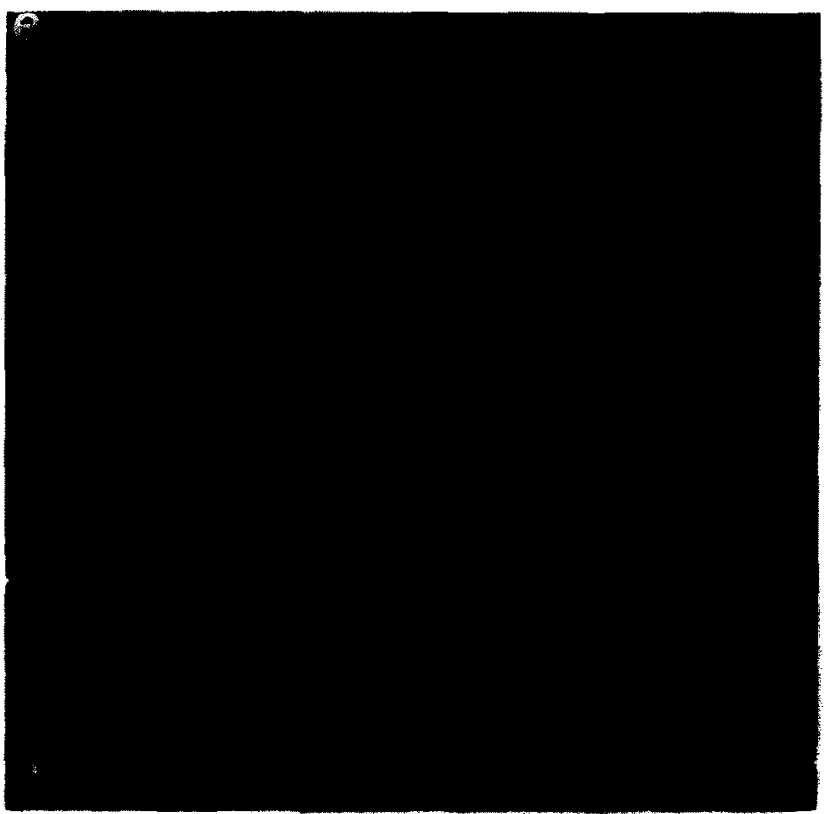

Fig. 1 continued (e-g). Photomicrographs showing immunofluorescent and immunoperoxidase staining of stereocilia in the organ of Corti and chick basilar papilla. (e) Immunofluorescence staining of stereocilia in the ampule of the guinea pig vestibular system by KHRI-5 (scale bar $=10 \mu \mathrm{m}$ ). (f) Control guinea pig cochlea incubated with $\mathrm{SP} 2 / 0$ and second antibody (scale bar $=10 \mu \mathrm{m}$ ). (g) Immunoperoxidase staining of stereocilia in the chick saccule using KHRI-4 (scale har $=10 \mu \mathrm{m})$.
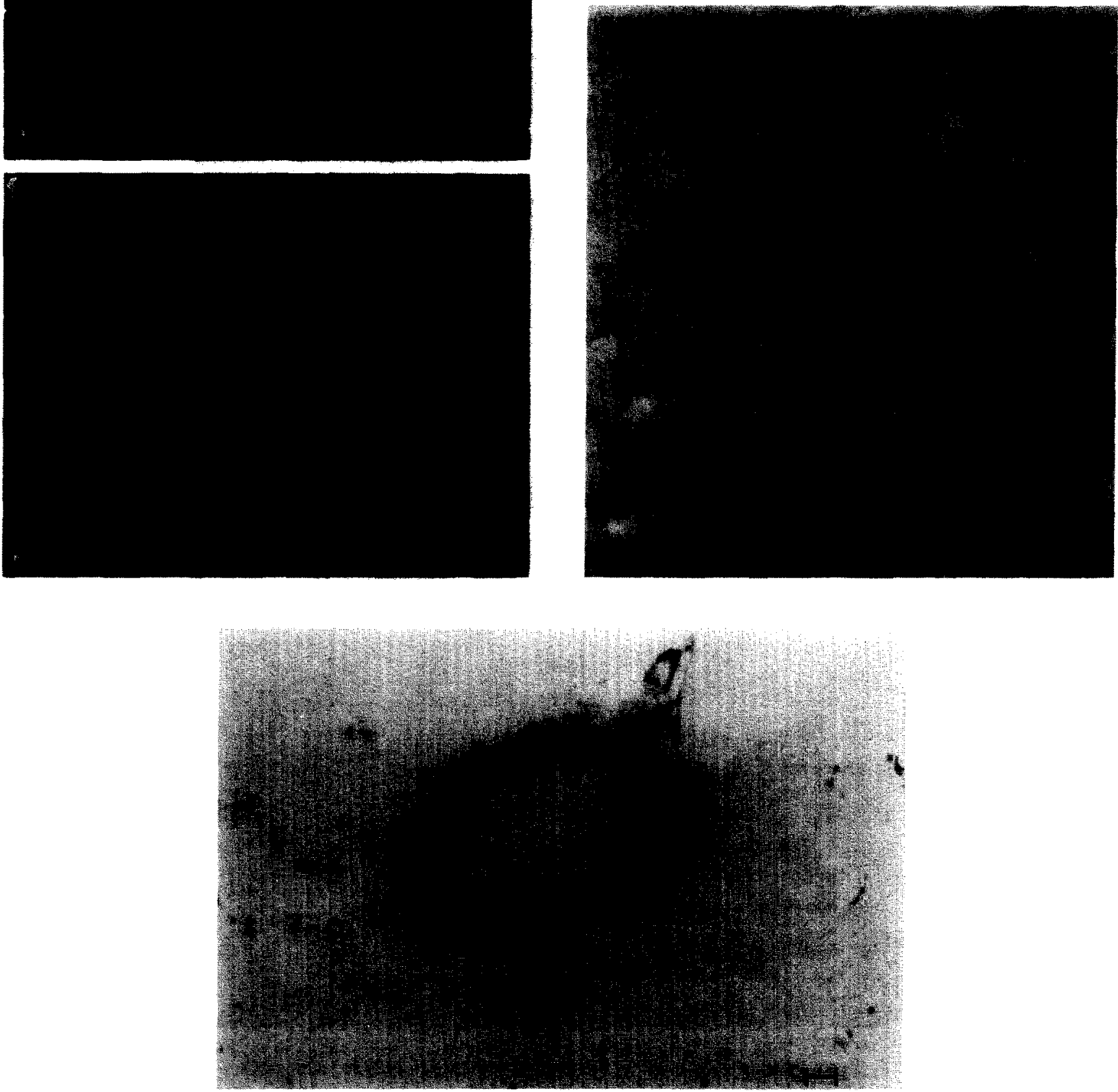

Fig. 2. Immunoperoxidase staining of a frozen section of guinea pig brain by KHRI-4. Only the smooth muscle cells in the arteriole were stained (scale bar $=1 \mu \mathrm{m}$ ). 

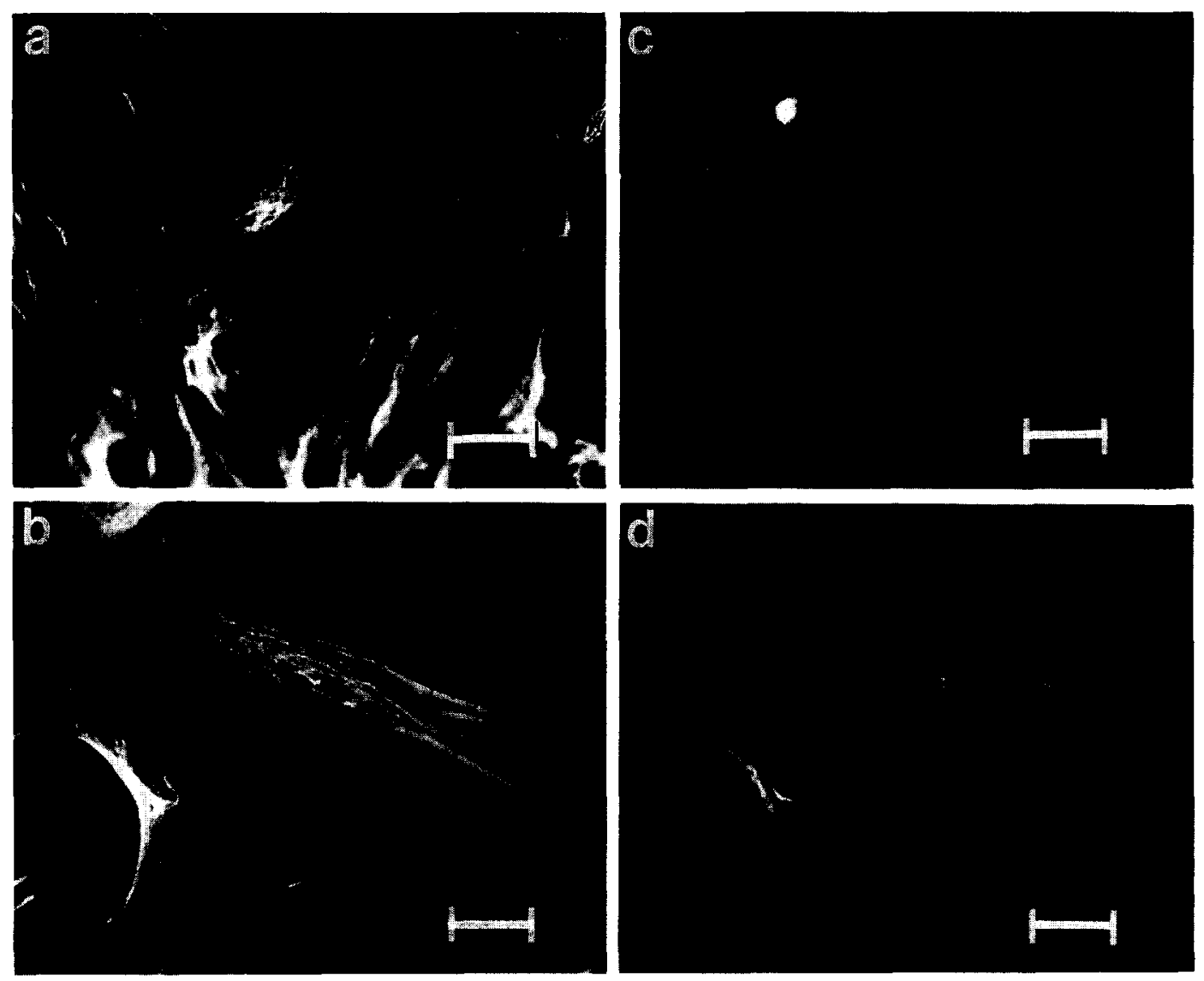

Fig. 3. Immunofluorescence dual staining of acetone fixed guinea pig skin fibroblasts with either KHRI-4 or -5 and fluorescein labeled phalloidin. Fibroblasts stained with KHRI-4 (a) or KHRI-5 (b) and rhodamine conjugated goat anti-mouse Ig. The same slides were also stained with phalloidin to detect filamentous actin $(\mathrm{c}$ and $\mathrm{d})($ scale bar $=10 \mu \mathrm{m})$.

staining of non-inner ear tissues was lost more readily with antibody dilution than was that obtained with stereocilia.

Because of the labeling we observed in the smooth muscle layers of some tissues, we felt that the antigen(s) we were detecting in the stereocilia might also be expressed in cultured cells of mesodermal origin. Expression of the same gene product in a cell type that could be grown in culture would facilitate its further study and characterization. For this reason we established and examined guinea pig skin fibroblast cultures. In fibroblast cultures fixed with acetone, antibodies KHRI-4 and KHRI-5 produced a staining pattern reminiscent of cytoskeletal structures (Fig. 3a, 3b). Double labeling experiments showed that the staining patterns were similar to but not identical with the distribution of filamentous actin structures labeled with phalloidin (Fig. 3c, 3d). Gencrally, KHRI-5 staincd the cytoskeletal elements more extensively than KHRI-4. In both cases, the fibrous staining pattern tended to go around rather than over the nuclei. No labeling was obtained when the fibroblasts were not acetone fixed and permeabilized prior to incubation with the primary antibody.

\section{Antibody staining of proteins on Western blots}

In Western blots run under non-reducing conditions, KHRI-4 identified two bands of approximately $195 \mathrm{kDa}$ and $230 \mathrm{kDa}$ in extracts of guinea pig cochlea, vestibular tissue, gut, fibroblasts and tongue (Fig. 4a). The KHRI-4 epitope must be altered by the reduction of sulfhydral bonds because the antibody did not bind to blots of cochlear extracts electrophoresed under reducing conditions. The $\sim 230 \mathrm{kDa}$ subunit appears to be labile to proteolytic degradation since even in the presence of multiple protcasc inhibitors this band becomes weak or absent in some experiments. In gels run under either reducing or nonreducing conditions, 
KHRI-5 binds to a band of $\sim 200-210 \mathrm{kDa}$ in extracts of cochlea, gut, fibroblasts and tongue (Fig. 4b). As can be appreciated in Fig. $4 \mathrm{~b}$, the $200 \mathrm{kDa}$ myosin molecular weight standard was also stained by both of these antibodies. The amount of antigen detected by KHRI-5 in vestibular extracts appears to be very low since we failed to detect this band in vestibular extracts in multiple experiments. Similar results to those shown in Fig. 4b were obtained with KHRI-5 on Western blots run under reducing conditions except that the band from gut was more prominent under reducing conditions.

\section{Immunoprecipitation}

In immunoprecipitation experiments with KHRI-4, bands of $\sim 195$ and $\sim 230 \mathrm{kDa}$ were observed that corresponded to the bands found in Western blots (Fig. 5). Immunoprecipitation experiments with KHRI-5 revealed new information since this antibody precipitated three bands of $\sim M_{\mathrm{r}} 200-210,230$ and $250 \mathrm{kDa}$ (Fig.
$5 b$ ), whereas only the $200-210 \mathrm{kDa}$ band had been detected in Western blots.

\section{Discussion}

The aims of this study were to generate monoclonal antibodies against inner ear sensory cell components as a means of identifying proteins expressed in the sensory cells but not in other cell types in the inner ear. Such proteins could likely have important roles in the sound transduction process and therefore their identification and characterization will add to our knowledge of the structure-function relationships in the auditory system. The reagents generated from this type of study will also be useful in examining pathologic changes at the molecular level.

In our previous study immunization of mice with guinea pig inner ear tissues proved to be useful for raising cochlear antibodies, however, only antibodies to supporting cells were obtained in those experiments (Zajic et al., 1991). We reasoned that since hair cells are phylogenetically conserved structures, mice and

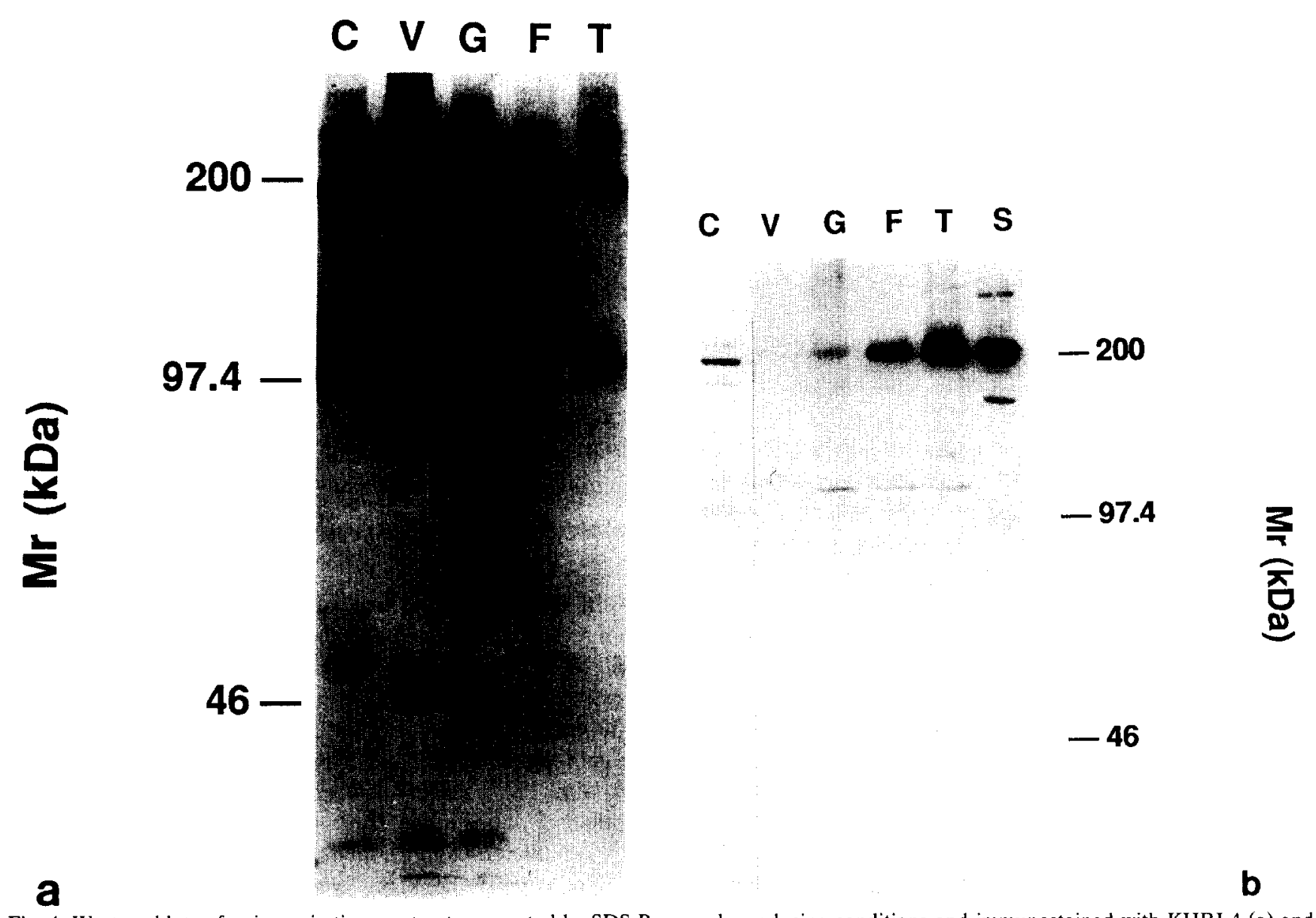

Fig. 4. Western blots of guinea pig tissue extracts separated by SDS-Page under reducing conditions and immunostained with KHRI-4 (a) and KHRI-5 (b). C-cochlea, V-vestibular system, G-gut, F-fibroblasts, T-tongue, S-molecular weight standards. 


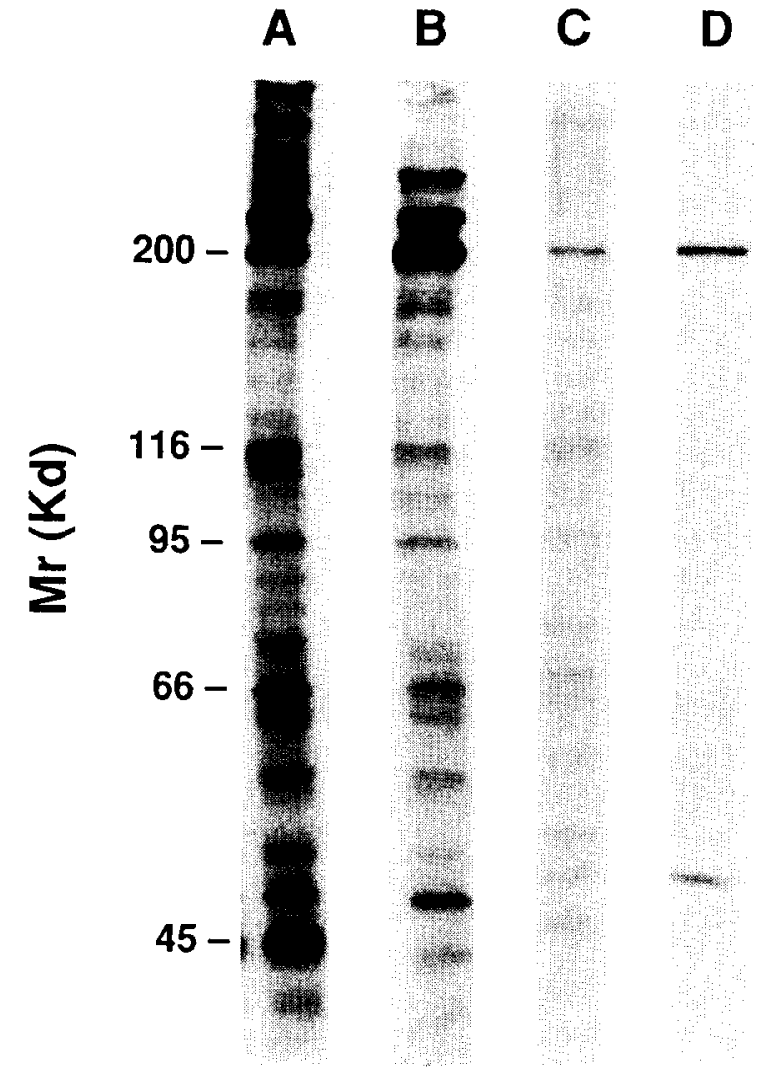

KHRI-4 KHRI-5 $1 \mathrm{H}_{12} \quad \mathrm{RxM}$

Fig. 5. Immunoprecipitation of S-35 methionine-labeled polypeptides from guinea pig fibroblasts by KHRI-4 (lane A) and KHRI-5 (lane B). KHRI-4 precipitates a doublet of $\sim 195$ and $\sim 230 \mathrm{kDa}$ whereas KHRI-5 precipitates three bands of $\sim 200-210, \sim 230$ and $\sim 250$ $\mathrm{kDa}$. Lanes $\mathrm{C}$ and $\mathrm{D}$ are control immunoprecipitation experiments. In lane $\mathrm{C}, 1 \mathrm{H} 12$ a control IgM monoclonal antibody and the rabbit anti-mouse Ig sera and protein A were used and in lane D only the rabbit anti-mouse Ig sera $(\mathrm{RxM})$ with protein $A$ was used.

guinea pigs might be too closely related to generate a strong immunogenic challenge for such structures. In more divergent species small differences in the primary structure of conserved proteins should exist and immunization with tissue from more distantly related animals should improve our chances of obtaining an immune response to hair cell antigens. In fact, immunization with inner ear tissues from divergent species was previously shown by us (Orozco et al., 1990) and others (Richardson et al., 1988) to be followed by the development of circulating serum antibodies to stereocilia. Therefore in this investigation we employed crossspecies immunization of mice with hair cells from chickens, frogs and guinea pigs to generate murine monoclonal antibodies to hair cell structures.

Our results indicate that this immunization scheme was successful. The molecules carrying the epitopes for the KHRI-4 and -5 mAbs are conserved phylogenetically, since the antibodies bind to stereocilia of both guinea pig and chick cochlear hair cells. Furthermore, the antigens are also conserved in the stereocilia of hair cells in the phylogenetically older vestibular system. The binding pattern we observed with KHRI-4 and -5 is similar to antibody reactivity observed in other studies (Orozco et al., 1990, Richardson et al., 1988). We did not observe this type of staining with numerous control antibodies of both IgG and IgM classes which rules out a non-selective stickiness of the stereocilia as a trivial explanation for these results. A light piping artifact as discussed by Egelman (1981) can be excluded because we obtained the same results with both rhodamine and DAB for visualization of bound antibodies. Furthermore, in experiments not shown, immunofluorescent labeling on cross-sections was restricted to the stereocilia. We did not observe staining of frog neuromast stereocilia, and the reasons for this are not clear. It may be that these antigenic structures are not present in frogs; alternatively, our methods may have been too insensitive to detect the antigen in the frog tissue.

Many laboratories have contributed to our knowledge of the structural components of stereocilia. For example, actin is known to be present in hair cells, especially in the stereocilia, of different species (Flock and Cheung, 1977; Flock et al., 1981, 1982; Slepecky and Chamberlain 1986; Sobin and Flock, 1981, 1983; Thorne et al., 1987; Zenner, 1981, 1986). It was suggested that hair cells contain a smooth muscle-like isoactin (Slepecky and Chamberlain, 1986) and other contractile protein(s). Drenckhahn (Drenckhahn et al., 1985) found a $200 \mathrm{kDa}$ protein in hair cell enriched chicken cochlea. This band was myosin immunoreactive and co-migrated with lymphocyte myosin heavy chain, identified by immunoblotting of human lymphocytes. KHRI-4 and KHRI-5 bind to bands of $195 / 230$ and $\sim 200-210 \mathrm{kDa}$ relative molecular mass respectively in guinea pig cochlea, chick basilar papilla and guinea pig fibroblasts. This is close to the molecular mass of $200 \mathrm{kDa}$ reported for muscle myosin. Whether or not stereocilia contain myosin is still subject to debate. Antibodies to non-muscle myosin from calf thymus labeled the cuticular plate of inner and outer hair cells and of vestibular hair cells in guinea pigs (Drenckhahn et al., 1985). Similar staining was observed using human platelet myosin antibodies. However, Drenckhahn et al. (1982) and others (Sans et al., 1989) did not find labeling of stereocilia with antimyosin antibodies. Macartney et al. (1980) reported immunofluorescent staining of guinea pig stereocilia and faint immunofluorescence in the cuticular plate using an antibody raised in rabbits against human smooth muscle myosin. Some have suggested that this could have been a light piping artifact (Egelman, 1981) or a glutaraldehyde fixation artifact. Sans et al. (1989) recently reported that hair cells (but not stereocilia) contain a smooth muscle-like myosin. Biochemical 
characterization of the stereocilia and the cuticular plate of hair cells by other investigators did not demonstrate proteins in the $200-230 \mathrm{kDa}$ region in chick stereocilia using high-salt detergent preparations and Western blotting (Tilney et al., 1989). This is in contrast to our results and might be due to different methodological procedures. For example, this group used 8 to $10 \%$ gels which resolve high molecular mass proteins less well than the $7 \%$ percent gels we used, and they studied mostly lower molecular weight bands which they acknowledged might be due to proteolysis. We found that variability in our preparations i.e loss of high molecular mass bands and the appearance of lower mass forms was associated with failure to carefully control for proteolysis and that the $230 \mathrm{kDa}$ band identified by KHRI-4 is particularly labile. It is possible that some of the low molecular weight bands identified by others (e.g. Tilney et al., 1989) could represent proteolytic products of the higher molecular weight bands we are studying.

The structures identified by our mAbs (or molecules with similar structures defining the same epitopes) are also present in other tissues, as indicated by ELISA, immunocytochemistry and Western blot results. This finding may assist in determining the nature and function of these antigens in the auditory system since we may be identifying proteins with knowil structure and function in other tissues. Furthermore the ability to analyze the same proteins in a cultured cell model increases our ability to manipulate the system, to label the proteins and to confirm by additional methods the relative molecular mass and nature of these proteins without sacrificing large numbers of animals. In cultured fibroblasts double immunofluorescent labeling assays with phalloidin, a marker for filamentous actin, reveals a similar but distinct pattern from that obtained by antibody labeling with KHRI-4 and -5 and indicates that these mAbs identify proteins closely associated with cytoskeletal elements. These assays also demonstrated that the antigens defined by KHRI- 4 and -5 in hair cells and fibroblasts are internal antigens since permeablization was essential to obtain immunolabeling.

We have not yet completely identified the molecular structures that carry the KHRI-4 and -5 epitopes. Our Western blotting and immunoprecipitation experiments indicate that these antibodies bind to structures with a higher molecular weight than actin. However, the similarity in the distribution of our antigens with that of actin, has led us to consider the possibility that these antibodies might define molecular structures that bind to or interact with actin either in the hair cell stereocilia or in the cytoskeleton of fibroblasts. In Western blots KHRI-4 identifies two bands p195/230 and KHRI-5 stains one prominent band of approximately $200-210 \mathrm{kDa}$. Thus the structures identified by
KHRI-4 and -5 appear to be similar but distinct from one another. This is consistent with the difference in patterns of distribution we observed in fibroblasts in which KHRI-5 stains structures that appear to extend nearly to the cell membrane while KHRI-4 gives a more limited staining distribution. Since Western blots indicate that the antigenic complex identified by KHRI-4 has the same electrophoretic mobility in cochlea, vestibular system, gut and fibroblasts it is likely that these proteins are similar in structure and function in different tissues. To further examine these structures we used immunoprecipitation from labeled fibroblast extracts. KHRI-4 immunoprecipitates the same p195/230 heterodimer observed on Western blots. However with KHRI-5 we consistently immunoprecipitate a trimolecular complex consisting of bands of roughly $200-210,230$ and $250 \mathrm{kDa}$. This indicates that the epitope is probably expressed on the 200-210 $\mathrm{kDa}$ subunit stained in the Western blots but that this protein is non-covalently asssociated with two other proteins that are co-precipitated by the same antibody. We are now preparing to determine whether these protein bands are known proteins. Possible candidates, based on the molecular mass, include a subtype of myosin $\left(M_{\mathrm{r}}=200 \mathrm{kDa}\right)$ (Drenckhahn et al., 1985), spectrin $\left(M_{\mathrm{r}}=240-260 \mathrm{kDa}\right)$ (Bennett, 1989) and talin $\left(M_{\mathrm{r}}=230 \mathrm{kDa}\right)$ (Burridge et al., 1987). The KHRI-4 and -5 antibodies bind to the myosin molecular weight standard in Western blots suggesting that myosin, or a protein that co-purifies with myosin, carries the same epitope(s) as the proteins in stereocilia and fibroblasts. Drenckhahn et al. (1985) also found $M_{\mathrm{r}} 240-260 \mathrm{kDa}$ polypeptides which may represent spectrin-like components. The $275 \mathrm{kDa}$ antigen defined by Richardson et al. (1990) has a similar but distinct distribution in stereocilia to those defined by KHRI-4 and -5 . In fact our $260 \mathrm{kDa}$ protein precipitated by KHRI-5 may be the protein chain identified by Richardson's antibody but the apparent difference in distribution may be because our antibody binds to a different chain of the same trimolecular complex. The distribution of spectrin and talin in fibroblasts are also each distinct from what we observed with KHRI-4 and -5 but since only the protein carrying the antibody-binding epitope will be stained in immunofluorescent labeling experiments we cannot rule out that these membrane anchoring proteins are not part of the multimolecular complex. Co-precipitation experiments with other serological reagents to known proteins will help to clarify if these proteins are part of the complex we have identified.

Although the proteins we identified with KHRI-4 and -5 appear to be internal antigens and thus seem unlikely to perturb function, antibodies with similar binding specificity in cochlea have been noted in the circulation of animals that developed hearing losses after immunization with inner ear tissue (Richardson 
et al., 1988; Richardson et al., 1990; Orozco et al., 1990). We have considered the possibility that antibodics to these internal structurcs might have a potentiating effect on primary damage to stereocilia injured by other noxious stimuli. We plan to investigate whether these epitopes are revealed in damaged cochlea where one of the earliest signs of damage is loss of turgor in the stereocilia. Through such investigations we may gain further knowledge about the pathogenesis of progressive hearing loss following trauma or inner ear infection.

\section{Acknowledgments}

The authors are indebted to Dr. Sanford Bledsoe and Ms. Susan Allen for expert assistance with the preparation of frog tissues for immunization and screening purposes as well as for the preparation of cross sections of frog neuromasts for immunocytochemistry. Supported by NIH PO1 DC 00078. Dr. Ptok is the recipient of a fellowship from the Deutsche Forschungsgemeinschaft.

\section{References}

Altschuler, R.A., Hoffman, D.W., Reeks, K.A. and Fex, J. (1985a) Localization of dynorphin B-like and alpha-neoendorphin-like immunoreactivities in the guinea pig organ of Corti. Hear. Res. $17,249-258$.

Altschuler, R.A., Reeks, K.A., Marangos, P.J. and Fex, J. (1985b) Neuron-specific enolase-like immunoreactivity in inner hair cells but not outer hair cells in the guinea pig organ of Corti. Brain Res. 327, 379-384.

Bennett, V. (1989) The spectrin-actin junction of erythrocyte membrane skeletons. Biochim. Biophys. Acta. 988, 107-121.

Burridge, K., Molony, L. and Kelly, T. (1987) Adhesion plaques: Sites of transmembrane interaction between the extracellular matrix and the actin cytoskeleton. J. Cell. Sci. (Suppl. 8), 211-229.

Drenckhahn, D., Kellner, J., Mannherz, H.G., Groschel-Stewart, U., Kendrick-Jones, J. and Scholey, J. (1982) Absence of myosin-like immunoreactivity in stereocilia of cochlear hair cells. Nature 300 , $531-532$.

Drenckhahn, D., Schaefer, T. and Prinz, M. (1985) Actin, myosin, and associated proteins in the vertebrate auditory and vestibular organs: Immunocytochemical and biochemical studies. In: D.G. Drescher (Ed.), Auditory Biochemistry, Charles C Thomas, Springfield, IL, pp. 317-335.

Egelman, E. (1981) Problem of light piping in immunofluorescence studies. Nature 294, 674.

Fex, J. and Altschuler, R.A. (1981) Enkephalin-like immunoreactivity of olivocochlear nerve fibers in cochlea of guinea pig and cat. Proc. Natl. Acad. Sci. USA 78, 1255-1259.

Fex, J., Kachar, B., Rubio, J.A., Parakkal, M.II. and Altschuler, R.A. (1985) Glutaminase-like immunoreactivity in the organ of Corti of guinea pig. Hear. Res. 17, 101-113.

Fex, J. and Altschuler, R.A. (1986) Neurotransmitter-related immunocytochemistry of the organ of Corti. Hear. Res. 22, 249-263.

Flock, A. and Cheung. H.C. (1977) Actin filaments in sensory hairs of inner ear receptor cells. J. Cell. Biol. 75, 339-343.
Flock, Å., Cheung, H.C., Flock, B. and Utter, G. (1981) Three sets of actin filaments in sensory cells of the inner ear. Identification and functional orientation determined by gel electrophoresis, immunofluorescence and electron microscopy. J. Neurocytol. 10, $133-147$.

Flock, $\AA$., Bretscher, A. and Weber, K. (1982) Immunohistochemical localization of several cytoskeletal proteins in inner ear sensory and supporting cells. Hear. Res. 7, 75-89.

Hsu, S.M., Raine, L. and Fanger, H. (1981) Use of avidin-biotincomplex $(\mathrm{ABC})$ in immunoperoxidase techniques: A comparison between $\mathrm{ABC}$ and unlabeled antibody (PAP) procedures. J. Histochem. Cytochem. 29, 577.

Johnson, D.A. and Elder, J.H. (1983) Antibody directed to determinants of a Maloney virus-derived MCF GP70 recognizes a thymic differentiation antigen. J. Exp. Med. 159, 1751-1756.

Kimmel, K.A. and Carey, T.E. (1986) Altered expression in squamous carcinoma cells of an orientation-restricted epithelial antigen detected by monoclonal antibody A9. Cancer Res. 46, 26142623.

Kohler, G. and Milstein, C. (1975) Continuous cultures of fused cells secreting antibody of predefined specificity. Nature 256, 495-497.

Laemmli, U.K. (1970) Cleavage of structural proteins during the assembly of the head of bacteriophage T4. Nature 227, 680 .

Macartney, J.C., Comis, S.D. and Pickles, I.O. (1980) Is myosin in the cochlea a basis for active motility? Nature 288, 491-492.

Orozco, C.R., Niparko, J.P. Richardson, B.C., Ptok, M. and Altschuler, R.A. (1990) Experimental model of immune mediated hearing loss employing cross-species immunization. Laryngoscope $100,941-947$.

Richardson, G.P., Bartolami, S. and Russel, I.J. (1988) Production of an antiserum specific for the apical surfaces of avian hair cells. Abstr. Inner Ear Biology Workshop.

Richardson, G.P., Bartolami, S. and Russel, I.J. (1990) Identification of a $275-\mathrm{kD}$ protein associated with the apical surfaces of sensory hair cells in the avian inner ear. J. Cell. Biol. 110, 1055-1066.

Sans, A., Atger, P., Cavadore, C. and Cavadore, J.-C. (1989) Immunocytochemical localization of myosin, tropomyosin and actin in vestibular hair cells of human fetuses and cats. Hear. Res. 40, $117-126$.

Schacht, J. and Zenner, H.P. (1987) Evidence that phosphoinositides mediate motility in cochlear outer hair cells. Hear. Res. 31, $155-159$.

Slepecky, N. and Chamberlain, S.C. (1986) Correlative immuno-electron-microscopic and immunofluorescent localization of actin in sensory and supporting cells of the inner ear by use of a low-temperature embedding resin. Cell. Tissue Res. 245, 229-235.

Sobin, A. and Flock, A. (1981) Sensory hairs and filament rods in vestibular hair cells of the waltzing guinea pig. Organization and identification of actin. Acta. Otolaryngol. (Stock). 911, 247-254.

Sobin, A. and Flock, §. (1983) Immunohistochemical identification and localiization of actin and fibrin in vestibular hair cells in the normal guinea pig and in a strain of the waltzing guinea pig. Acta. Otolaryngol. (Stock). 96, 407-412.

Spitz, M., Spitz, L., Thorpe, R. and Eugui, E. (1984) Intrasplenic primary immunization for the production of monoclonal antibodies. J. Immunol. Methods 70, 39-43.

Spitz, M. (1986) 'Single-shot' intrasplenic immunization for the production of monoclonal antibodies. Methods Enzymol. 121, 33-41.

Takasaka, T. and Smith, C.A. (1971) The structure and organization of the pigeon's basilar papilla. J. Ultrastruct. Res. 35, 20-65.

Tanaka, K. and Smith, C.A. (1978) Structure of the chicken's inner ear: SEM and TEM study. Am. J. Anat. 153, 251-271.

Thorne, P.R., Carlisle, L., Zajic, G., Schacht, J. and Altschuler, R.A. (1987) Differences in the distribution of F-actin in outer hair cells along the organ of Corti. Hear. Res. 30, 253-265.

Tilney, M.S., Tilney, L.G., Stephens, R.E., Merte, C., Drenckhahn, D., Cotanche, D.A. and Bretscher, A. (1989) Preliminary bio- 
chemical characterization of the stereocilia and cuticular plate of hair cells of the chick cochlea. J. Cell. Biol. 109, 1711-1723.

Towbin, H., Staehlin, T. and Gordon, J. (1979) Electrophoretic transfer of proteins from polyacrylamide gels to nitrocellulose sheets. Procedure and some applications. Proc. Natl. Acad. Sci US^ 73, 2599.

Zajic, G. and Schacht, J. (1987) Comparison of isolated outer hair cells from five mammalian species. Hear. Res. 26, 249-256.

Zajic, G., Nair, T.S., Ptok, M., Van Waes, C., Altschuler, K.A.,
Schacht, J. and Carey, T.E. (1991) Monoclonal antibodies to inner ear antigens: I. Antigens expressed by supporting cells of the guinea pig cochlea. Hear. Res. 52, 59-72.

Zenner, H.P. (1981) Cytoskeletal and muscle-like elements in cochlear hair cells. Arch. Otorhinolaryngol. 230, 81-92.

Zenner, H.P. (1986) Molecular structure of hair cells. In: D.E. Hoffmann, R.A. Altschuler and R.P. Bobbin (Eds.), Neurobiology of hearing: The cochlea, Raven Press, New York, NY, USA, pp. $1-22$. 